\title{
REGIONAL LOW-FLOW PERFUSION PROVIDES CEREBRAL CIRCULATORY SUPPORT DURING NEONATAL AORTIC ARCH RECONSTRUCTION
}

Frank A. Pigula, MD

Edwin M. Nemoto, PhD

Bartley P. Griffith, MD

Ralph D. Siewers, MD
Objective: Because of concerns regarding the effects of deep hypothermia and circulatory arrest on the neonatal brain, we have developed a technique of regional low-flow perfusion that provides cerebral circulatory support during neonatal aortic arch reconstruction. Methods: We studied the effects of regional low-flow perfusion on cerebral oxygen saturation and blood volume as measured by near-infrared spectroscopy in 6 neonates who underwent aortic arch reconstruction and compared these effects with 6 children who underwent cardiac repair with deep hypothermia and circulatory arrest. Results: All the children survived with no observed neurologic sequelae. Near-infrared spectroscopy documented significant decreases in both cerebral blood volume and oxygen saturations in children who underwent repair with deep hypothermia and circulatory arrest as compared with children with regional low-flow perfusion. Reacquisition of baseline cerebral blood volume and cerebral oxygen saturations were accomplished with a regional low-flow perfusion rate of $20 \mathrm{~mL} \cdot \mathrm{kg}^{-1} \cdot \mathrm{min}^{-1}$. Conclusions: Regional low-flow perfusion is a safe and simple bypass management technique that provides cerebral circulatory support during neonatal aortic arch reconstruction. The reduction of deep hypothermia and circulatory arrest time required may reduce the risk of cognitive and psychomotor deficits. (J Thorac Cardiovasc Surg 2000;119:331-9)
T he use of deep hypothermia and circulatory arrest (DHCA) in children who have undergone complex aortic arch reconstruction has been considered unavoidable. Although the duration of safe DHCA remains unknown, 30 to 45 minutes is considered the upper limit. ${ }^{1,2}$ We know from our transplantation experience that many organs will tolerate several hours of cold ischemia; however, the brain does not. Evidence of overt brain injury may be found in up to $10 \%$ of children who have undergone DHCA, although subtle but detectable neuropsychiatric injuries may occur in up to

From the Department of Pediatric Cardiothoracic Surgery, Children's Hospital of Pittsburgh, Pittsburgh, Pa.

Read at the Twenty-fifth Annual Meeting of The Western Thoracic Surgical Association, Olympic Valley (Lake Tahoe), Calif, June 23-26, 1999.

Received for publication June 29, 1999; revisions requested July 19, 1999; revisions received Aug 11, 1999; accepted for publication Aug 13, 1999.

Address for reprints: Frank A. Pigula, MD, Department of Pediatric Cardiothoracic Surgery, Room 2820, 2 Main, Children's Hospital of Pittsburgh, Pittsburgh, PA 15213 (E-mail: Pigulaf@ heart.chp.edu)

Copyright (C) 2000 by Mosby, Inc.

$0022-5223 / 2000 \$ 12.00+0 \quad \mathbf{1 2 / 6 / 1 0 2 4 7 9}$
$50 \% .^{3-7}$ These figures are all the more alarming when the potential impact both to the individual and to society are considered. Individual cost (in terms of lost personal potential) and societal cost (measured in resource usage) may accrue over decades after a neonatal brain injury.

Because of these concerns, we have developed a technique of regional perfusion during neonatal aortic arch reconstruction. ${ }^{8}$ Guided by near-infrared spectroscopy (NIRS), this technique drastically reduces circulatory arrest time and maintains cerebral blood volume and oxygen saturation while providing the same surgical exposure obtained during DHCA. We report our experience using this technique in 6 neonates who underwent extensive aortic arch reconstructions.

\section{Methods}

Surgical technique. Six children underwent neonatal aortic arch reconstruction with regional low-flow perfusion (RLFP) (Table I). In these children, standard arch reconstruction was performed with minor modifications. On initiation of cardiopulmonary bypass through the ductus arteriosus (through the pulmonary artery) and the right atrial appendage, the patient is cooled to $18^{\circ} \mathrm{C}$. The ductus is snared around the arterial cannula, and preparatory dissection is performed. This 
Table I. Demographics

\begin{tabular}{|c|c|c|c|c|c|}
\hline Patients & Weight $(\mathrm{kg})$ & Age & Diagnosis & $C A T$ (min) & $R L F P($ min $)$ \\
\hline \multicolumn{6}{|l|}{ With RLFP } \\
\hline 1 & 2.4 & $7 \mathrm{~d}$ & Aortic valve atresia, VSD, aortic hypoplasia & 6 & 58 \\
\hline 2 & 3.5 & $5 \mathrm{~d}$ & $\begin{array}{l}\text { D-TGA, hypoplastic right ventricle, VSD, } \\
\text { aortic hypoplasia }\end{array}$ & 6 & 41 \\
\hline 3 & 2.1 & $7 \mathrm{~d}$ & HLHS & 10 & 47 \\
\hline 4 & 3.4 & $5 \mathrm{~d}$ & HLHS & 7 & 49 \\
\hline 5 & 3.1 & $3 \mathrm{~d}$ & HLHS & 9 & 49 \\
\hline 6 & 3.6 & $4 \mathrm{~h}$ & HLHS, restrictive atrial septum & 17 & 52 \\
\hline Mean $( \pm \mathrm{SD})$ & $3(.6)$ & & & $9(4)$ & $49(6)$ \\
\hline \multicolumn{6}{|c|}{ Without RLFP } \\
\hline 1 & 4.4 & $5 \mathrm{~d}$ & L-TGA, hypoplastic right ventricle & 59 & NA \\
\hline 2 & 4.1 & $240 \mathrm{~d}$ & $\begin{array}{l}\text { PAPVR intrathoracic kidney, pulmonary } \\
\text { sequestration }\end{array}$ & 26 & NA \\
\hline 3 & 3.1 & $4 \mathrm{~d}$ & HLHS & 60 & NA \\
\hline 4 & 3.5 & $7 \mathrm{~d}$ & D-TGA, VSD & 9 & NA \\
\hline 5 & 5.5 & $100 \mathrm{~d}$ & VSD & 32 & NA \\
\hline 6 & 2.8 & $2 \mathrm{~d}$ & TAPVR & 40 & NA \\
\hline Mean $( \pm$ SD) & $3.9(1)$ & & & $38^{*}(20)$ & \\
\hline
\end{tabular}

$C A T$, Circulatory arrest; VSD, ventricular septal defect; TGA, transposed great arteries; $N A$, not applicable; PAPVR, partial anomalous pulmonary venous return; $T A P V R$, total anomalous pulmonary venous return.

${ }^{*} P=.006$.

Table II. Change in CrBVI and $\mathrm{CrSO}_{2}$ during RLFP or circulatory arrest as compared with baseline values

\begin{tabular}{lcccc}
\hline & $N$ & Circulatory arrest (min) & $\Delta \mathrm{CrSO}_{2}$ & $\Delta \mathrm{CrBVI}$ \\
\hline With RLFP & 6 & $9 \pm 4(6-17)$ & $-0.8 \pm 5.26$ & $-1.4 \pm 2.7$ \\
Without RLFP & 6 & $38 \pm 20^{*}(9-60)$ & $-33.5 \pm 14.6^{\dagger}$ & $-19.2 \pm 14.3^{\ddagger}$ \\
\hline
\end{tabular}

$\Delta \mathrm{CrSO}_{2}$, Change in relative $\mathrm{CrSO}_{2}$ from baseline; $\triangle \mathrm{CrBVI}$, change in relative CrBVI from baseline. Values are mean $\pm \mathrm{SD}$. Numbers in parenthesis are ranges.

${ }^{*} P=.006$.

${ }^{\dagger} P=.002$.

$\stackrel{\square}{\ddagger}=.03$.

includes the aortic arch, extending distal to ductal insertion, and the brachiocephalic vessels. The innominate artery is controlled at its bifurcation into the right common carotid and subclavian arteries, and the proximal anastomosis of the anticipated modified Blalock shunt is performed $(3.5-\mathrm{mm}$ polytetrafluoroethylene*). The shunt is left long and clamped. Cardiopulmonary bypass is halted; the brachiocephalic vessels are snared, and the patient's blood is exsanguinated into the reservoir. The arterial and venous cannulas are removed, and the atrial septectomy is performed through the atrial appendage. At this time, the arterial cannula is inserted into the shunt and, after careful deairing, tied into position. With the right common carotid artery temporarily occluded to avoid air embolism, RLFP is initiated at $5 \mathrm{~mL} \cdot \mathrm{kg}^{-1} \cdot \mathrm{min}^{-1}$ and increased every 2 to 3 minutes until cerebral blood volume has reached precirculatory arrest levels. A small metaltipped bullet sucker placed through the atrial appendage scavenges blood returning to the heart (Fig 1). The remainder of the arch reconstruction was performed at $18^{\circ} \mathrm{C}$ under condi-

${ }^{*}$ Gore-Tex conduit, registered trademark of W. L. Gore \& Associates, Inc, Flagstaff, Ariz. tions of RLFP. A bloodless operative field is maintained by the brachiocephalic snares, the right atrial scavenger, and a small angled crossclamp on the descending aorta. The purpose of the crossclamp is 2-fold: By elevating the distal-most portion of the reconstruction, visualization and access are improved, and back bleeding from the descending aorta is prevented. On completion of arch reconstruction, the neoaorta and right atrial appendage are recannulated, and full cardiopulmonary bypass is resumed.

Control patients. Six patients who underwent heart surgery with DHCA for a variety of congenital heart conditions were also studied with NIRS (Table I).

Anesthetic and perfusion management. Anesthetic and cardiopulmonary bypass management was standardized and was the same for both groups of patients. Anesthetic technique was consistent and used high-dose opiates for all patients. During cooling, cardiopulmonary bypass flow was maintained between 2.0 and $2.5 \mathrm{~L} \cdot \mathrm{min}^{-1} \cdot \mathrm{m}^{-2}$ to achieve a rectal temperature of $18^{\circ} \mathrm{C}$. Blood gas management was by the alpha-stat technique.

Monitoring. Standard hemodynamic monitoring was applied to all children. Arterial blood pressure was monitored 


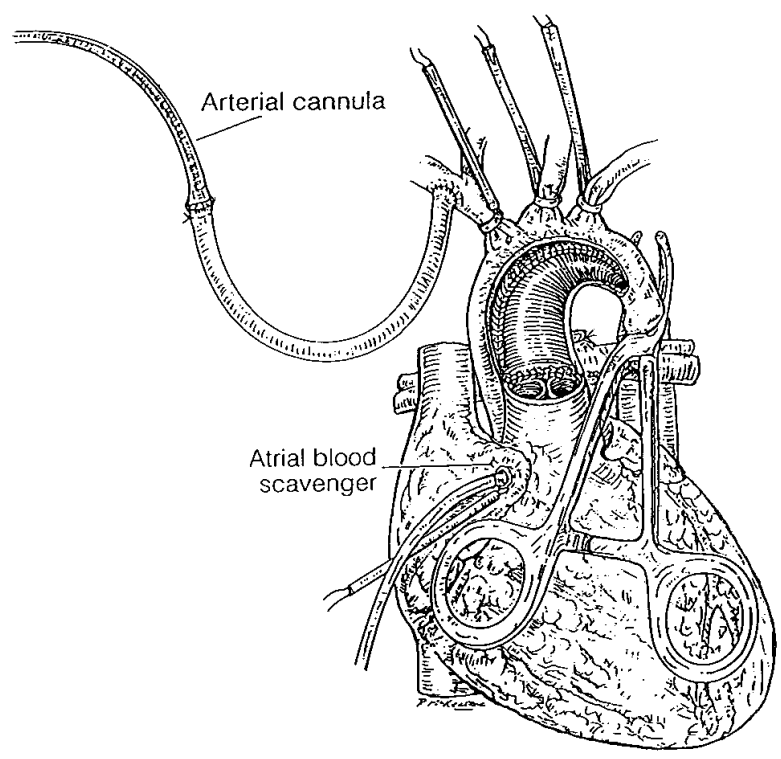

Fig 1. Depiction of the operative field during aortic arch reconstruction with RLFP. Arterial inflow is through the cannulated shunt after the anastomosis to the innominate artery is performed. Exposure is maintained by the brachiocephalic snares, a clamp on the descending aorta, and the right atrial blood scavenger. The $3.5-\mathrm{mm}$ polytetrafluoroethylene graft will admit an $8 \mathrm{~F}$ or $10 \mathrm{~F}$ arterial cannula (Medtronic BioMedicus, Eden Prairie, Minn). On completion of the neoaorta, deairing is accomplished by removing the aortic clamp.

by a left radial artery catheter. Rectal and esophageal temperature probes were inserted for temperature management. After informed consent was obtained, all children underwent intraoperative monitoring of relative cerebral blood volume index $(\mathrm{CrBVI})$ and oxygen saturation $\left(\mathrm{CrSO}_{2}\right)$ with NIRS (INVOS 4100; Somanetics Corp, Troy, Mich; NIRO 500; Hamamatsu Phototomics, Hamamatsu, Japan). A sensor placed on the right lateral forehead monitored $\mathrm{CrSO}_{2}$ and CrBVI. Relative CrBVI and percent oxyhemoglobin saturation were displayed in real time, and these data were used to direct the rate of RLFP. Data were downloaded and stored for later analysis.

Data acquisition. Standard hemodynamic monitoring was applied to all patients. Patients who underwent DHCA without RLFP served as control subjects, and $\mathrm{CrBVI}$ and $\mathrm{CrSO}_{2}$ were compared with those of neonates who underwent aortic arch reconstruction with RLFP. Arterial blood pressure was obtained through a left radial arterial line. After the induction of anesthesia and before the draping of the patient, NIRS sensors were placed over the right frontoparietal area of the brain. Data were sampled every 2 seconds and saved to disk. Data acquisition began with sensor placement and ended with patient transport to the intensive care unit. Baseline CrBVI and $\mathrm{CrSO}_{2}$ were obtained after the institution of full cardiopulmonary bypass support and after core cooling but

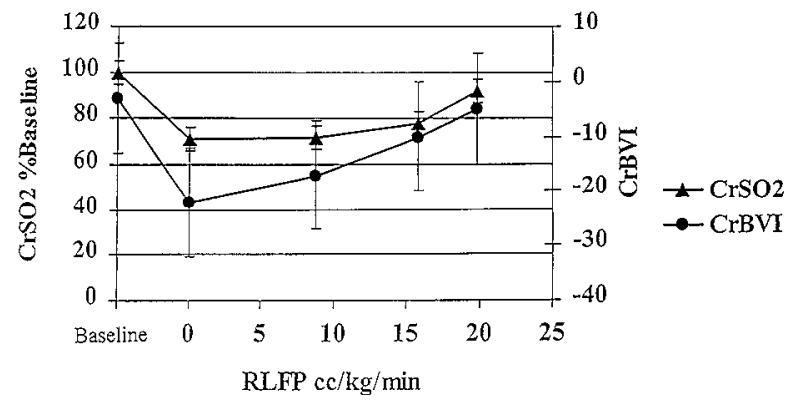

Fig 2. Relative $\mathrm{CrBVI}$ and relative $\mathrm{CrSO}_{2}$ as a function of RLFP rate. Reacquisition of baseline CrBVI ( ) occurs consistently at about $20 \mathrm{~mL} \cdot \mathrm{kg}^{-1} \cdot \mathrm{min}^{-1}$, and is mirrored by return to baseline $\mathrm{CrSO}_{2}(\mathbf{\Lambda})$.

before circulatory arrest or RLFP. Data in Table II are presented as change in $\mathrm{CrBVI}(\Delta \mathrm{CrBVI})$ and $\mathrm{CrSO}_{2}\left(\Delta \mathrm{CrSO}_{2}\right)$ during RLFP or circulatory arrest as compared with baseline values. Percent return to baseline was measured when both relative $\mathrm{CrBVI}$ and $\mathrm{CrSO}_{2}$ stabilized on RLFP.

Statistical analyses were done by analysis of variance for repeated measures for normally distributed data and the Tukey procedure for significant differences. Values presented are mean \pm standard deviation unless otherwise stated.

\section{Results}

There were no deaths in either group of patients. Mean duration of RLFP was $49 \pm 6$ minutes (range, 41 58 minutes), and there were no complications related to RLFP. With RLFP, a short period of DHCA is required for decannulations, recannulations, and atrial septectomy when necessary. This time, however, is very brief and consistent ( $9 \pm 4$ minutes) and was significantly shorter than that required by the children in the control group. Furthermore, the children who underwent DHCA demonstrated a significantly greater fall in both relative $\mathrm{CrBVI}(\Delta \mathrm{CrBVI})$ and $\mathrm{CrSO}_{2}\left(\Delta \mathrm{CrSO}_{2}\right)$ as compared with patients whose condition was supported with RLFP (Table II).

Because of concerns about cerebral hyperperfusion, we used real-time NIRS data to gradually increase the rate of RLFP until CrBVI was restored to baseline levels (obtained on full cardiopulmonary support). Restoration of baseline CrBVI consistently occurred with a RLFP rate of $20 \mathrm{~mL} \cdot \mathrm{kg}^{-1} \cdot \mathrm{min}^{-1}$. Furthermore, with the restoration of $\mathrm{CrBVI}, \mathrm{CrSO}_{2}$ was also restored to baseline values (Fig 2). This is in contrast to children in the control group who experienced a prompt and predictable decline in both $\mathrm{CrBVI}$ and $\mathrm{CrSO}_{2}$ (Figs 3 and 4).

During the brief period of circulatory arrest required for atrial septectomy and recannulation, radial artery pressure was $0 \mathrm{~mm} \mathrm{Hg}$. With RLFP and the restoration 


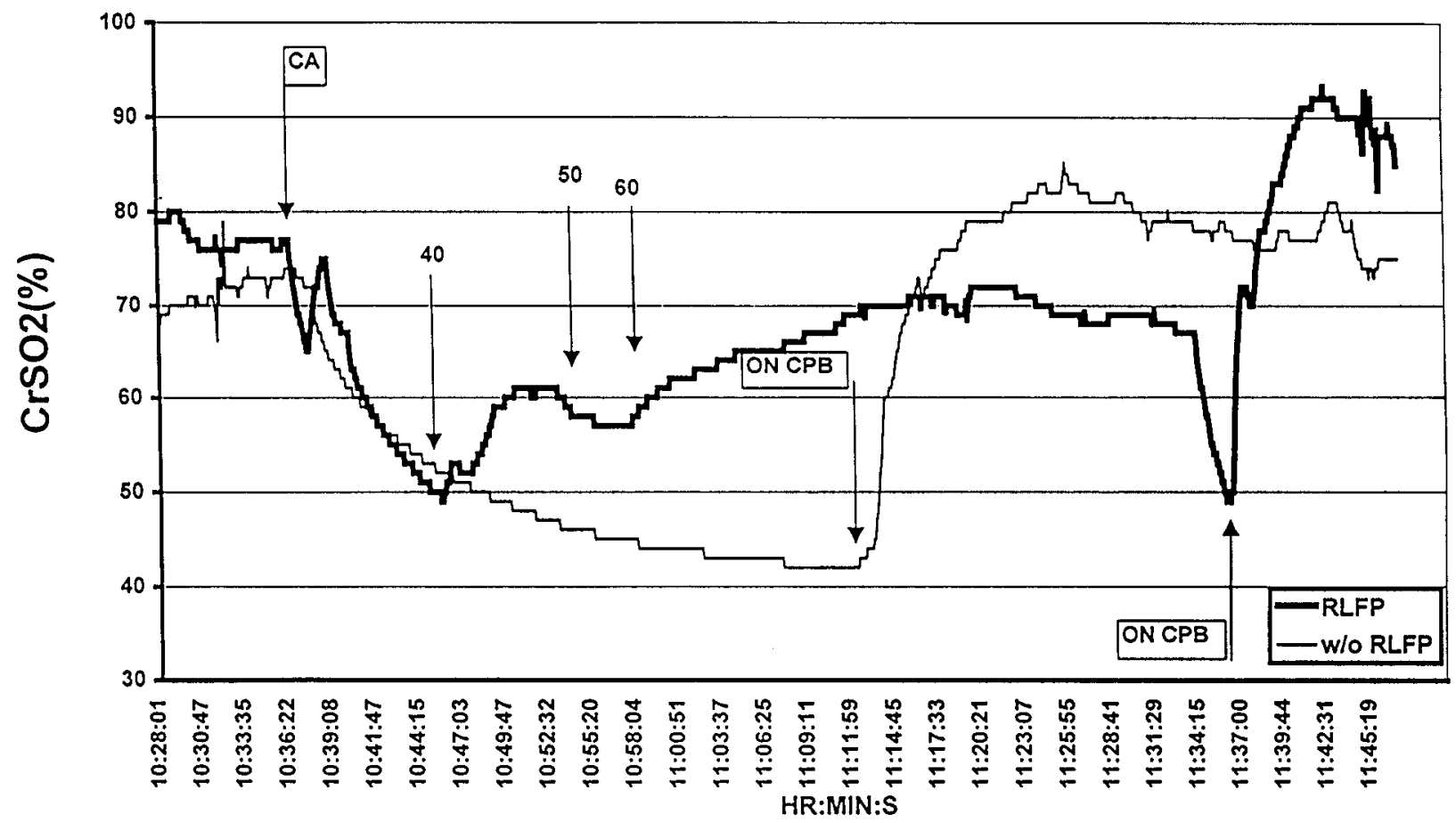

Fig 3. NIRS. Depicts relative $\mathrm{CrSO}_{2}$ in 2 infants. The first is a 3.1-kg 5-day-old infant who underwent a Norwood operation for HLHS (heavy line). The second neonate (thin line) is a 2-day-old infant who underwent a repair of total anomalous pulmonary venous return under circulatory arrest. Although the rate of desaturation between the 2 patients is similar, the institution of RLFP in the neonate who underwent the Norwood operation restores $\mathrm{CrSO}_{2}$ to baseline levels. Sharp declines in $\mathrm{CrSO}_{2}$ in the hypoplast on RLFP at circulatory arrest $(C A)$ and cardiopulmonary bypass $(C P B)$ correlate with decannulation and atrial septectomy and with recannulation after reconstruction of the neoaorta. 40 , Initiation of RLFP at $40 \mathrm{~mL} / \mathrm{min} ; 50,50 \mathrm{~mL} / \mathrm{min} ; 60,60 \mathrm{~mL} / \mathrm{min}$.

of baseline $\mathrm{CrBVI}$ and $\mathrm{CrSO}_{2}$, the left radial artery catheter measured an average of $22 \mathrm{~mm} \mathrm{Hg}$ (16-28 $\mathrm{mm} \mathrm{Hg}$ ).

\section{Discussion}

Because operative death rates for congenital heart defects have declined, concern has focused on the neurologic consequences of operations for congenital heart disease. Ferry ${ }^{9}$ has reported that up to $25 \%$ of infants who underwent cardiac surgery with hypothermic cardiopulmonary bypass had some form of neuropsychiatric injury. Concern escalates when circulatory arrest is added to hypothermic cardiopulmonary bypass. Citing autopsy evidence, Glauser and colleagues ${ }^{10}$ reported neurologic injury in 10 of 13 patients (77\%) who underwent DHCA for hypoplastic left heart syndrome (HLHS). These injuries included cerebral necrosis, periventricular leukomalacia, brain stem necrosis, and intracranial hemorrhage. They found that brain injury was associated with DHCA times that exceeded 40 minutes. In an effort to further define the incidence and magnitude of neuropsychiatric injury that resulted from DHCA in a clinical setting, Newberger and colleagues ${ }^{11}$ studied the effects of DHCA versus low-flow cardiopulmonary bypass in 171 infants who were younger than 3 months of age. They also found that DHCA resulted in neuropsychiatric injury, manifested by an increased propensity for perioperative seizures and long-term psychomotor and cognitive impairment and that this impairment was related to the duration of DHCA.

Thus although DHCA may be a valuable technique, efforts to limit the duration of DHCA are necessary. Although the safe duration of DHCA is unclear, most clinical and experimental evidence suggests that hypothermia $\left(16^{\circ} \mathrm{C}-18^{\circ} \mathrm{C}\right)$ provides adequate neuroprotection for 30 to 45 minutes. ${ }^{1,12,13}$ Although this duration may appear to be well tolerated, the studies that are cited reinforce a compelling intuitive desire to reduce DHCA time to an absolute minimum. Reports exploring the minimum circulatory requirements of the brain supported by cardiopulmonary bypass suggest that low 


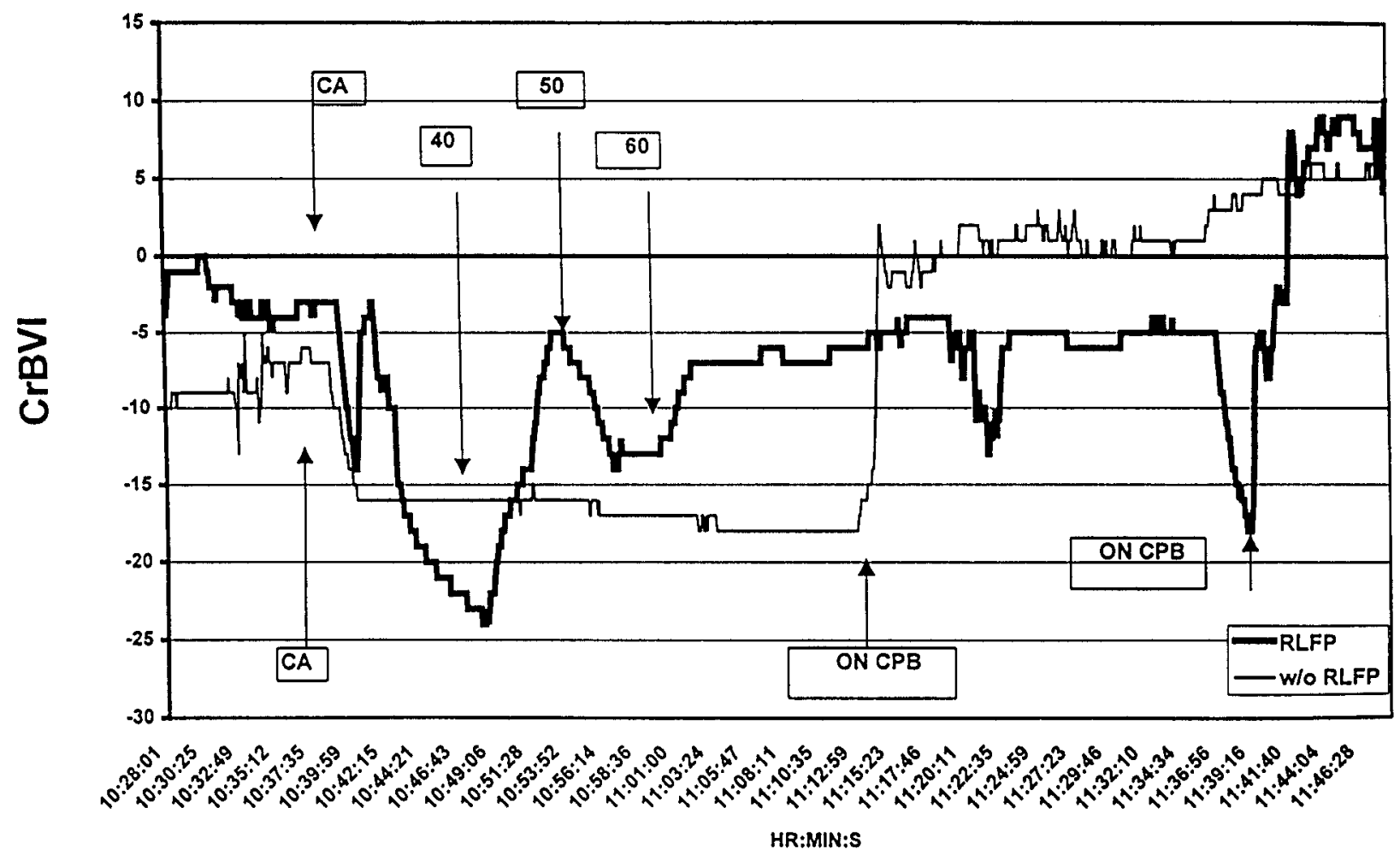

Fig 4. CrBVI, NIRS data. Depicts relative CrBVI in same 2 infants (HLHS with RLFP [heavy line]; total anomalous pulmonary venous return with circulatory arrest [thin line]). RLFP restores relative CrBVI to near baseline levels, although CrBVI remains depressed in the neonate who underwent circulatory arrest. As with relative $\mathrm{CrSO}_{2}$, sharp declines in CrBVI in the hypoplast on RLFP occurring at circulatory arrest $(C A)$ and cardiopulmonary bypass $(C P B)$ correlate with decannulation and atrial septectomy and recannulation after construction of the neoaorta. 40 , initiation of RLFP at $40 \mathrm{~mL} / \mathrm{min} ; 50,50 \mathrm{~mL} / \mathrm{min} ; 60,60 \mathrm{~mL} / \mathrm{min}$.

flow is better than no flow; common sense dictates that less circulatory arrest time is better than more. ${ }^{11,14}$

With this in mind, alternatives to DHCA have been sought. Asou and colleagues ${ }^{15}$ and Sano and colleagues ${ }^{16}$ have described a similar technique but provided no data to support the contention that the brain was sustained. McElhinney and colleagues ${ }^{17}$ described technical modifications that minimize DHCA duration in infants undergoing the Damus-Kaye-Stansel procedure. This recent interest in alternatives to DHCA underscores a growing awareness that neurologic injury is a serious concern during heart surgery in neonates and infants. Although much time and effort have been directed toward developing strategies to minimize the neurologic injury associated with DHCA, we suggest the simplest and most direct strategy is to minimize exposure to the insult as much as possible.

RLFP accomplishes this goal by providing cerebral circulatory support and greatly reducing the duration of DHCA required for neonatal arch reconstruction. This already brief (average, 9 minutes) duration may be reduced even further by the initiation of cardiopulmonary bypass through the shunt. We have no experience with this modification but are concerned about the potential for cerebral hyperperfusion and somatic hypoperfusion in the presence of a diminutive aorta, particularly at normothermia.

NIRS is a recent, noninvasive technology capable of measuring changes in tissue chromophores, such as hemoglobin..$^{18}$ NIRS exploits the differences in absorption peaks between oxygenated and deoxygenated hemoglobin and provides information on the changes, or relative differences, in these compounds over time. ${ }^{19}$ Again, these are relative changes; absolute values require the measurement of the path length of the NIRS signal, which is not readily available with current technology. The relative $\mathrm{CrBVI}$ and $\mathrm{CrSO}_{2}$ are mainly determined by the cerebral venous blood because it comprises about $75 \%$ of intracranial blood volume (arterial, approximately 20\%; capillaries, approximate- 
ly $5 \%) .{ }^{20}$ However, there is a strong clinical correlation between the NIRS signal and flow in the internal carotid artery, and NIRS has been used in neonatologic procedures and in pediatric heart surgery. ${ }^{21-23}$

The use of NIRS technology has guided our RLFP rate and enabled us to document that regional perfusion of the brain provides the same $\mathrm{CrBVI}$ and $\mathrm{CrSO}_{2}$ that are provided by standard cardiopulmonary bypass support. Although data defining the lower limit of blood flow to the human neonatal brain are not available, our finding that $20 \mathrm{~mL} \cdot \mathrm{kg}^{-1} \cdot \mathrm{min}^{-1} \mathrm{RLFP}$ is required for $\mathrm{CrBVI}$ and $\mathrm{CrSO}_{2}$ restitution is consistent with animal studies. Using a dog model, Miyamoto and colleagues ${ }^{24}$ concluded that the optimal perfusion rate for the brain at $20^{\circ} \mathrm{C}$ was $30 \mathrm{~mL} \cdot \mathrm{kg}^{-1} \cdot \mathrm{min}^{-1}$, with oxygen debt and anaerobic metabolism when flow rate was less than $15 \mathrm{~mL} \cdot \mathrm{kg}^{-1} \cdot \mathrm{min}^{-1}$. In sheep, Swain and colleagues ${ }^{25}$ showed preservation of energy substrates with flows as low as $10 \mathrm{~mL} \cdot \mathrm{kg}^{-1} \cdot \mathrm{min}^{-1}$. Because of concerns about cerebral hyperperfusion with the use of RLFP, we believed it appropriate to limit the perfusion rate such that baseline CrBVIs (measured by NIRS on full-flow hypothermic cardiopulmonary bypass) were maintained. In this way NIRS allows us, for the first time, to quantify blood flow requirements of the neonatal brain at hypothermic temperatures. Thus for the human neonate, the data suggest that $20 \mathrm{~mL} \cdot \mathrm{kg}^{-1}$. $\min ^{-1}$ (delivered with this technique and using alphastat blood gas management) provides adequate cerebral circulatory support.

This is an important qualification because we did not quantify the flow distribution (ie, right subclavian vs right common carotid arteries) during RLFP. Flow distribution will depend on the relative resistances in the perfused vascular beds. Although it has been shown that cerebral vascular resistance increases with hypothermia, systemic vascular resistance can be expected to increase even more. ${ }^{26}$ Thus we believe that most of the RLFP preferentially enters the cerebral circulation and that intracranial and extracranial arterial collateral connections between the head the left radial artery are required to explain a left radial arterial pressure of $22 \mathrm{~mm} \mathrm{Hg}$. Furthermore, our observation of substantial back bleeding from the descending thoracic aorta leads us to speculate that RLFP provides some degree of somatic circulatory support in addition to cerebral support. This finding presumably results from an extensive network of arterial collaterals between the upper body and the descending aorta in the neonate. This degree of collateralization is apparent clinically by the low incidence of paraplegia encountered in neonatal coarctation repair. ${ }^{27}$ These collaterals would include not only intracranial connections through the circle of Willis but also extracranial arteries, vertebral arteries, internal thoracic arteries, and intercostal arteries. Somatic perfusion through these collaterals may serve to attenuate the metabolic burden of DHCA, placing neonates in a better physiologic position to tolerate the postoperative period. Although RLFP under DHCA may increase edema formation, we have not identified this as a clinical problem. Indeed, despite a low threshold for leaving the sternum open after a stage I Norwood operation, this was required in only 1 of 4 patients who were palliated for HLHS. These findings deserve further investigation because circulatory support of the subdiaphragmatic viscera may impart a significant survival advantage.

Although extensive neonatal aortic arch reconstruction may be required in a variety of conditions, it is most commonly performed in stage I Norwood operation for HLHS. ${ }^{28,29}$ It is in this group of patients that important secondary benefits of RLFP should be recognized. By supporting the brain during construction of the neoaorta, the time allowed for the performance of a technically precise reconstruction is extended. This is a critically important point because the success of the Norwood operation hinges on the achievement of 3 surgical goals:

1. Maintainence of satisfactory coronary perfusion

2. Unobstructed and hemostatic construction of the neoaorta

3. Appropriate pulmonary blood flow

The importance of achieving these goals has been illustrated by Bertram and colleagues, ${ }^{30}$ who reviewed the autopsy results in 122 patients who died after a Norwood operation. They found that $27 \%$ of the deaths were from impaired coronary perfusion, $14 \%$ of the deaths were from neoaortic obstruction, $7 \%$ of the deaths were from bleeding, and $36 \%$ of the deaths were from inappropriate (excessive or inadequate) pulmonary blood flow. Allowing more time for the meticulous construction of the neoaorta, without the pressing need to limit circulatory arrest time, should make these goals more attainable.

As with HLHS, neonates who undergo complex aortic surgery resulting in biventricular repair may also be expected to benefit. This was in fact the case for patient 1 (Table I), who was born with aortic valve atresia, aortic hypoplasia, and a large ventricular septal defect with a satisfactory left ventricle. This child underwent a Norwood-type reconstruction of the aorta, baffling of the ventricular septal defect to the neoaorta, and homograft reconstruction from the right ventricle to the pulmonary arteries. Thus RLFP may extend the surgeon's 
capabilities when dealing with a variety of aortic pathologic conditions.

In summary, RLFP represents a new bypass management technique that significantly reduces the exposure of the neonatal brain to circulatory arrest during aortic arch reconstruction. This technique is simple and, based on the NIRS data, provides cerebral circulatory support equivalent to that provided by full-flow cardiopulmonary bypass. Furthermore, initial observations suggest that RLFP may provide some degree of somatic circulatory support as well. The reduction of DHCA time required for neonatal aortic arch reconstruction can be expected to reduce the risk of cognitive and psychomotor deficits and may reduce perioperative deaths.

\section{REFERENCES}

1. Kirklin JW, Barratt-Boyes BG. Hypothermia, circulatory arrest, and cardiopulmonary bypass. In: Kirklin JW, Barratt-Boyes BG, editors. Cardiac surgery. 2nd ed. New York: John Wiley \& Sons; 1993. p. 74.

2. Wragg RE, Dimsdale SE, Moser KM, Daily PO, Dembitsky WP, Archibald C. Operative predictors of delirium after pulmonary thromboendarterectomy. J Thorac Cardiovasc Surg 1988;96:5249.

3. Brunberg JA, Reilly EL, Doty DB. Central nervous system consequences in infants of cardiac surgery using deep hypothermia and circulatory arrest. Circulation 1974;50(Suppl):II60-8.

4. Clarkson PM, MacArthur BA, Barratt-Boyes BG, Whitlock RM, Neutze JM. Developmental progress following cardiac surgery in infancy using profound hypothermia and circulatory arrest. Circulation 1980;62:855-61.

5. Ehyai A, Fenichel GM, Bender HW. Incidence and prognosis of seizures in infants after cardiac surgery with profound hypothermia and total circulatory arrest. JAMA 1984;252:3165-7.

6. Jonas RA, Wernovsky G, Ware J, et al. The Boston Circulatory Arrest Study: perioperative neurologic and developmental outcome after the arterial switch operation. Circulation 1992;86 (Suppl):I360.

7. Hickey PR. Neurologic sequelae associated with deep hypothermia circulatory arrest. Ann Thorac Surg 1998;65:S65-70.

8. Pigula FA, Siewers RD, Nemoto EM. Regional perfusion of the brain during neonatal aortic arch reconstruction. J Thorac Cardiovasc Surg 1999;117:1023-4.

9. Ferry PC. Neurologic sequelae of open-heart surgery in children. Am J Dis Child 1990;144:369-73.

10. Glauser TA, Rorke LB, Weinberg PM, Clancy RR. Acquired neuropathologic lesions associated with the hypoplastic left heart syndrome. Pediatrics 1990;85:991-1000.

11. Newberger JW, Jonas RA, Wernovsky G, et al. A comparison of the perioperative effects of hypothermic circulatory arrest versus low flow cardiopulmonary bypass. N Engl J Med 1993;329: 1057-64.

12. Treasure T, Naftel DC, Conger KA, et al. The effect of hypothermic circulatory arrest on cerebral function, morphology, and biochemistry. J Thoracic Cardiovasc Surg 1990;86:761-70.

13. Norwood WI, Norwood CR, Ingwall JS, et al. Hypothermic circulatory arrest. J Thorac Cardiovasc Surg 1979;78:823-30.

14. Soma Y, Hirotani T, Yozu R, et al. A clinical study of cerebral cir- culation during extracorporeal circulation. J Thorac Cardiovasc Surg 1989;97:187-93.

15. Asou T, Kado H, Imoto Y, et al. Selective perfusion technique during aortic arch repair in neonates. Ann Thorac Surg 1996;61: 1546-8.

16. Sano S, Kawada M, Yoshida H, et al. Norwood procedure to hypoplastic left heart syndrome. Jpn J Thorac Cardiovasc Surg 1998;46:1311-6.

17. McElhinney DB, Reddy VM, Silverman NH, Hanley FL. Modified Damus-Kaye-Stansel procedure for single ventricle, subaortic stenosis, and arch obstruction in neonates and infants: midterm results and techniques for avoiding circulatory arrest. J Thorac Cardiovasc Surg 1997;114:718-26.

18. Jobsis FF. Non-invasive infrared monitoring of cerebral and myocardial oxygen sufficiency and circulatory parameters. Science 1977;198:1264-7.

19. Wrey S, Cope M, Delphy DT, Wyatt JJ, Reynolds EO. Characterization of the near-infrared absorption spectra of cytochrome aa3 and haemoglobin for the non-invasive monitoring of cerebral oxygenation. Biochim Biophys Acta 1988;933:1484-92.

20. McHedlishuli G. Cerebral arterial behavior providing constant cerebral blood flow, pressure and volume. In: Bevan JA, editor. Arterial behavior and circulation in the brain. New York: Plenum Press; 1986. p. 42-95.

21. Kirkpatrick PJ, Smeilewski P, Whitfield PC, et al. An observational study of near-infrared spectroscopy during carotid endarterectomy. J Neurosurg 1995;83:1111-2.

22. Wahr, JA, Tremper KK, Samra S, Delphy DT. Near-infrared spectroscopy: theory and applications. J Cardiothorac Vasc Anesth 1996;10:406-18

23. Nollert G, Shin'oka T, Jonas RA. Near-infrared spectroscopy of the brain during cardiovascular surgery. Thorac Cardiovasc Surg 1998;46:167-75.

24. Miyamoto K, Kawashima Y, Matsuda H, et al. Optimal perfusion flow rate for the brain during deep hypothermic cardiopulmonary bypass at $20^{\circ} \mathrm{C}$. J Thorac Cardiovasc Surg 1986;92:1065-70.

25. Swain JA, McDonald TJ, Griffith PK, et al. Low flow hypothermic cardiopulmonary bypass protects the brain. J Thorac Cardiovasc Surg 1991;192:76-83.

26. Kern FH, Ungerleider RM, Reves JG, et al. The effect of altering pump flow rate on cerebral blood flow and metabolism in infants and children. Ann Thorac Surg 1993;56:1366-72.

27. Brewer LA, Fosberg RA, Mulder GA, Verska JJ. Spinal cord complications following surgery for coarctation of the aorta. $\mathrm{J}$ Thorac Cardiovasc Surg 1972;64:36881.

28. Norwood WI, Kirklin JK, Sanders SP. Hypoplastic left heart syndrome: experience with palliative surgery. Am J Cardiol 1980;45: 87-91.

29. Bove EL. Current status of staged reconstruction for hypoplastic left heart syndrome. Pediatr Cardiol 1998;19:308-15.

30. Bartram U, Grunenfelder J, Van Praagh R. Causes of death after the modified Norwood procedure: a study of 122 postmortem cases. Ann Thorac Surg 1997:64:1795-902.

\section{Discussion}

Dr Frank Hanley (Berkeley, Calif). This is a very important manuscript, not because it describes a new technique; it does not. Asou and associates, in The Annals of Thoracic Surgery, described regional cerebral perfusion via a polytetrafluoroethylene graft for repair of complex arches in 1996. 
It is also not because this experience is particularly large or comprehensive. In 1997 our group presented repair of complex neonatal arches without circulatory arrest at the meeting of The American Association for Thoracic Surgery (AATS) and then subsequently published it in The Journal of Thoracic and Cardiovascular Surgery. This experience was subsequently updated at the AATS meeting last year with our experience in 80 infants in whom we used techniques that were similar to yours, but not identical. About half of those patients had HLHS.

There are two reasons why the manuscript is important. First, it addresses an evolving and controversial topic in congenital heart disease: Should DHCA continue to be used in repair of congenital heart disease? Some historical perspective is important here. Thirty years ago the pioneer surgeons who were developing cardiac surgery for neonates and infants used DHCA as a necessary and unavoidable adjunct to complex procedures in small infants. At that time, equipment, microsurgical technique, and experience did not allow any alternatives. As an aside, to emphasize this point we can look at the arterial switch operation. It is clear that the concept of that operation had been known for decades, but it was not until 1980 that a successful arterial switch was performed for transposition in neonates. The limitation was technical. Similarly, technical limitations in past decades regained the use of DHCA to achieve success in small infants. DHCA as a result was taught by the masters to the subsequent generation of pediatric heart surgeons, many of whom have simply accepted the fact that this practice was a necessary component of neonatal and infant repair. Even though the risks related to DHCA have been well documented, many surgeons consider this technique to be mandatory or at least preferred, especially in arch repair. This may have been true 30 years ago, but no longer is this technique necessary to repair even the most complex arch reconstructions.

The brain has evolved with its profound complexity over millions of years. It seems that it is a somewhat misplaced effort to spend millions in research money, not to mention the intellectual effort, in figuring out ways to reverse the profound physiologic and biochemical derangements induced by purposeful brain ischemia. Free radical spin traps and excitatory amino acid inhibitors are really only the tip of the iceberg in solving this very complex problem.

Why create a very complex problem using DHCA and then be faced with the profound additional problem of figuring out a way of solving it, when the problem itself can be completely avoided by eliminating the brain ischemia completely? It would seem that if a fraction of the money and research effort that have been put into studying ways to outsmart brain ischemia were put into developing relatively simple plumbing techniques of providing reliable continuous cerebral blood flow, we would solve this problem in a fraction of the time. DHCA is not necessary in modern practice, and it becomes clear that the research effort in brain ischemia, at least as it pertains to the practice of cardiac surgery, has been misplaced if we accept this fact. The cur- rent emphasis on outsmarting brain ischemia only makes sense if DHCA is absolutely necessary, and as you have shown in this study, it is not.

Old comfortable habits die hard. DHCA is comfortable and easy for many surgeons. This manuscript, therefore, represents an important addition to the growing number of groups moving away from DHCA, and you should be congratulated for this effort.

The second reason why this manuscript is important is that it is the first study that actually attempts to quantify cerebral blood flow and cerebral metabolism using continuous regional perfusion techniques. These data are badly needed to document the efficacy of the technique and to stimulate appropriate modifications of the technique as we move ahead.

I have three questions for you. First, your method of cannulating the pulmonary artery first and then switching to the polytetrafluoroethylene graft seems somewhat redundant. Why don't you simply put the graft on first, cannulate it, and perfuse continuously? You would not have to perform even a brief period of circulatory arrest.

Dr Pigula. Thank you for your comments. The reason we have done that is to simplify the technique. As you rightly pointed out, Asou and his associates did describe a technique similar to this. Although they did not provide any saturation data, they did provide some pressure data. In their technique they used two separate cannulations. For the sake of expediency and simplicity, we use one cannula and simply move it, accepting a brief period of circulatory arrest.

Dr Hanley. At least in patients undergoing the Norwood procedure, the arches rarely are truly interrupted, and I can say our technique is to directly cannulate into the head vessels with a very small arterial cannula, either the base of the innominate or the carotid artery, and perfuse that way right from the very beginning. We get excellent cooling using multiple temperature probes placed on different regions of the body. It is just another way to do it.

The second question relates to your method of documenting blood flow and metabolism. I, and possibly others, am not particularly familiar with the method and limitations of cerebral NIRS. Does it matter that you put the sensor lateralized to one side of the brain? Detractors of this technique may say that if you are perfusing the right side and you have your sensor on the right side, despite flow through the circle of Willis, the left side of the brain may be in danger. Does this method globally average the entire brain or is it biased to the side on which you put the sensor? Should you put the sensor on the other side? Should you be using tympanic membrane probes in both ears to see if there are shifts in temperature to obtain quantitative regional data?

Dr Pigula. That is a very good point. What we are measuring is a regional reflection of cerebral saturations and blood volume. Therefore, the answer is, yes, we should at least investigate what the results would be, for instance, on the left frontoparietal area. I suspect they are going to be the same, but I have not proven that.

Dr Hanley. Are you considering doing this in other arch 
problems that have two ventricles, such as interrupted aortic arch and other complex arch reconstructions?

Dr Pigula. Yes. Actually one of the patients in this report underwent biventricular repair. One of those patients was a neonate with aortic atresia and a hypoplastic arch just like a typical patient with HLHS; however, that baby had a left ventricle with a ventricular septal defect, and we did use this technique to do a biventricular repair at 8 days of age. I think it is justified under those circumstances in the face of a very complex aortic arch reconstruction necessitating a long period of DHCA.

Dr Christo Tchervenkov (Montreal, Quebec, Canada). As someone who also does quite a bit of neonatal aortic arch reconstruction, particularly in complex two-ventricle hearts, I endorse this trend away from DHCA. However, at the Montreal Children's Hospital we have gone in that direction a lot more cautiously than Dr Hanley's group has, for a number of reasons. DHCA was important historically in allowing pioneer surgeons to finally accomplish neonatal repairs and improve the survival of these patients. I believe that one of the most important determinants for survival and also for brain protection is the achievement of a complete and accurate anatomic repair. Therefore embracing surgical techniques that avoid circulatory arrest must not be done at all costs if they compromise the accuracy of the intracardiac repair or if those techniques might result in anatomic stenoses of the cerebral vessels.

In patients other than those with HLHS, we have placed the aortic cannula in the ascending aorta at the base of the innominate artery. At the time of doing the aortic arch repair, we advance the cannula without taking it out into the innominate artery for regional perfusion, while the aortic arch is repaired, and then pull it back into the ascending aorta for the rest of the operation, again without taking it out. Do you have any experience with the technique I just described in lesions other than HLHS?

Dr Pigula. No, sir, I do not.

Dr Tchervenkov. We have to be very cautious about direct cannulation of the innominate artery because of the possibility of causing significant stenosis in these small vessels in very small babies. While we embrace this trend, we also have to spend the time, as Dr Hanley suggested, to develop new cannulas and new techniques so that eventually we can safely avoid circulatory arrest in all patients.

Your technique involves transfer of the aortic cannula from the pulmonary artery to the shunt. This introduces the possibility of air embolization to the brain. Can you describe more precisely how you avoid air into the shunt, because you have to stop the circulation to transfer the cannula?

Dr Pigula. It is just another technical feature. A 3.5-mm polytetrafluoroethylene shunt will accept an 8 F or $10 \mathrm{~F}$ BioMedicus cannula. We carefully deair it by deairing the cannula and the shunt. Then, before opening the shunt, we just temporarily occlude the right common carotid artery, so even if there is any residual air left in the circuit, it will be directed down the right subclavian artery rather than to the brain.

To address your other concerns, which I share, I would argue that the longer and the more complex the aortic construction and the longer the potential for circulatory arrest, the better off you are with some form of support. With continued support you do not have the time constraints that you may have during circulatory arrest conditions, and your technical outcome may be better for that reason.

\section{Bound volumes available to subscribers}

Bound volumes of The Journal of Thoracic and Cardiovascular Surgery are available to subscribers (only) for the 2000 issues from the Publisher, at a cost of $\$ 134.00$ for domestic, $\$ 165.85$ for Canadian, and $\$ 155.00$ for international subscribers for Vol 119 (January-June) and Vol 120 (July-December). Shipping charges are included. Each bound volume contains a subject and author index and all advertising is removed. Copies are shipped within 60 days after publication of the last issue of the volume. The binding is durable buckram with the Journal name, volume number, and year stamped in gold on the spine. Payment must accompany all orders. Contact Mosby, Inc, Subscription Services, 11830 Westline Industrial Drive, St Louis, MO 63146-3318, USA; phone 800-453-4351 or 314-453-4351.

Subscriptions must be in force to qualify. Bound volumes are not available in place of a regular Journal subscription. 